\title{
Remote monitoring of patient recovery following lung cancer surgery: a messenger application approach
}

\author{
Xinghua Cheng, Yunhai Yang, Yang Shentu, Zhengping Ding, Qianjun Zhou, Qiang Tan, Qingquan Luo \\ Department of Oncology, Shanghai Lung Cancer Center, Shanghai Jiao Tong University Affiliated Chest Hospital, Shanghai, China \\ Contributions: (I) Conception and design: X Cheng; (II) Administrative support: Q Luo; (III) Provision of study materials or patients: X Cheng, Y \\ Yang, Y Shentu, Z Ding, Q Zhou, Q Tan; (IV) Collection and assembly of data: X Cheng; (V) Data analysis and interpretation: X Cheng, Q Luo; (VI) \\ Manuscript writing: All authors; (VII) Final approval of manuscript: All authors. \\ Correspondence to: Qingquan Luo, MD, PhD. Department of Oncology, Shanghai Lung Cancer Center, Shanghai Jiao Tong University Affiliated \\ Chest Hospital, 241 West Huai-Hai Road, Xuhui District, Shanghai 200030, China. Email: luoqingquan@hotmail.com.
}

\begin{abstract}
Background: Repeated assessment of patient recovery after discharge is challenging. This study used a popular messenger application to remotely collect patient self-reported symptoms and their severity so as to monitor patient recovery and identify the factors affecting the recovery of symptoms following lung cancer surgery.

Methods: This prospective observational study was conducted at a single tertiary lung cancer center in China between November 2018 and June 2019. Participants received demonstration videos and repeated symptom surveys regarding pain and cough severity (assessed using numeric rating scores of 0-10 for pain and 0-6 for cough) at 2, 4, 6, 8, and 12 weeks after discharge via a smartphone program bound to the WeChat application. Patients who responded to at least 3 of the 5 post-discharge surveys were included in this study. The data were analyzed to investigate the symptom recovery and its related factors.

Results: Of the 826 patients enrolled, 589 (71.3\%) responded to at least three surveys. The average pain score reduced from $4.1 \pm 2.5$ at 2 weeks to $2.2 \pm 2.0$ at 12 weeks $(\mathrm{P}<0.001)$. Factors associated with higher pain severity included the female gender, age over 60 years, thoracotomy, longer operation time ( $>90$ minutes), and prolonged chest tube drainage ( $>7$ days). The average cough score decreased from $2.34 \pm 1.30$ at 2 weeks to $1.93 \pm 1.26$ at 12 weeks $(\mathrm{P}<0.001)$. Being female and a prolonged operation time $(>90 \mathrm{~min})$ were related to increased cough severity. Sublobar resection and limited lymphadenectomy may contribute to lower cough severity post-surgery.
\end{abstract}

Conclusions: The messenger application-based remote monitoring successfully collected post-discharge symptom information and identified factors associated with recovery following lung surgery.

Keywords: Lung cancer surgery; symptom recovery; remote monitoring

Submitted Dec 02, 2020. Accepted for publication Jan 28, 2021.

doi: $10.21037 /$ jtd-21-27

View this article at: http://dx.doi.org/10.21037/jtd-21-27

\section{Introduction}

Globally, 200,000 patients undergo lung cancer surgery every year (1). Following major lung surgery, patients usually experience a reduced quality of life because of operation related symptoms such as pain and cough $(2,3)$. However, the recovery trajectory, in terms of duration and degree of these symptoms during the recovery period after surgery and its affecting factors remains unclear. While surgeons have strived to use less invasive techniques to minimize surgical trauma in selected patients (4), the benefits of these techniques are often empirical, and their impact on patient experience and recovery is poorly documented (4). Therefore, it is difficult for physicians to determine the suitability of these techniques in further improving the patient's experience following surgery $(5,6)$. 
Despite its importance, monitoring postoperative recovery after discharge remains challenging. Current lung cancer guidelines recommend the initiation of surveillance at 6 months post-surgery to detect signs of recurrence (7). However, most surgery-related symptoms are relieved by 6 months, and physicians may miss the critical window in which a patient's recovery experiences should be evaluated $(8,9)$. Although some studies have sought to address this problem, they either lacked continuous follow-up $(2,10)$ or were limited by small sample sizes $(3,8)$ as the repeated collection of symptom information through outpatient visits or telephone calls is highly time-consuming and laborintensive (11). Hereby, new methods to monitor surgery related symptoms during the routine 6 months surveillance are needed.

Notably, the subjective monitoring of symptoms by directly collecting patient-reported outcomes (PRO) has received increasing attention for its role in improving patient-centered care (12). It is considered necessary in evaluating surgery and other cancer treatments and acts in complement with traditional metrics $(11,13)$. In cancer patients, the addition of PRO in follow-up may reduce symptom severities of symptoms, increase tolerance to the treatment, detect early recurrence and improve survival $(5,12-15)$. Recently, the widespread use of smartphones has greatly increased accessibility to the internet, and this may facilitate the data collection of PROs (16) and enable the monitoring of symptoms in clinical practice following lung surgery. Therefore, we designed a smartphone program named "cloud ward" (registered software patent no. 2018SR891901) bound to the WeChat application (Tencent, China) to assist both in-hospital patient management and post-discharge surveillance by automatically sending multimedia material and PRO surveys to the patient's own WeChat account. WeChat is a multifunctional messenger application similar to Facebook and WhatsApp, with over 1 billion active users in China each month. This effectively capitalizes on an application that the patients already utilize rather than introducing an additional application.

The objective of this study was to remotely monitor the patient's symptoms during recovery following lung cancer surgery. Patient-reported symptomatic outcomes were collected through a messenger application and the factors affecting the recovery trajectory were identified. We present the following article in accordance with the STROBE reporting checklist (available at http://dx.doi.org/10.21037/ jtd-21-27).

\section{Methods}

\section{Study design and participants}

This single-center prospective cohort study was conducted in accordance with the Strengthening the Reporting of Observational Studies in Epidemiology (STROBE) guidelines (17). All consecutive adult patients (aged 18 years and older) who were scheduled for lung surgery at our department between November 2018 and June 2019 were approached for inclusion in this study. Patients were eligible if they had smartphones and were comfortable using the messenger application WeChat for completing the symptom-related surveys, either by themselves or with the help of at least one close relative. Digital consent was obtained after the patients agreed to connect their accounts with our departmental public service account on WeChat by scanning a quick response code. All patient information was strictly confidential and was used for research purposes only. This study conformed to the provisions of the Declaration of Helsinki (as revised in 2013), and was approved by the institutional Ethics Review Committee of the Shanghai Chest Hospital (approval number KSY1871).

\section{Collection of clinical and PRO data}

Once internet connection was established, patients immediately received a video demonstration of the program (supplemental video), with instructions on the PRO survey and other educational material pertaining to their surgery. Data on clinical variables, including gender, age, education status, location of residence, status of medical insurance, prior surgery, and primary malignant disease, were obtained from medical records and the registration survey to assess the factors associated with a patient's compliance in using this method for follow-up. Symptom-relevant PRO surveys and the video demonstration were sent to the patients at 2, 4, 6, 8, and 12 weeks following surgery. At each time point, the survey was sent thrice daily, until the patient responded. For patients who did not respond to the first round of surveys, a telephone call was made in order to assist with any problems encountered during the use of the program, and the patients were encouraged to complete the following surveys using their smartphones. Patients who were non- 
responsive to subsequent rounds of the survey were not further contacted.

\section{Outcome measures}

In our previous pilot survey which investigated "the most disturbing postoperative symptoms" in 213 patients one month after lung surgery, the following five most significant symptoms were identified: pain (33.8\%), cough (26.8\%), fatigue $(18.3 \%)$, shortness of breath $(14.1 \%)$, and constipation $(1.9 \%)$. Therefore, in the current study, pain and cough were selected as the main metrics for evaluating symptom recovery. Pain severity during the previous 24 hours was evaluated using a numeric rating score, with 0 denoting "not present", and 10 denoting "as bad as you can imagine" (3). Patients were asked to categorize their pain frequency, with 1 denoting "not present", 2 denoting "rare, less than $50 \%$ of awake time", 3 denoting "sometimes, more than $50 \%$ of awake time," and 4 denoting "always". Cough during the previous 24 hours was evaluated by a cough visual analog scale, with 0 denoting "no cough", and 5 denoting "worst possible cough" (18). Nurses and residents checked with the patients while they were still in the hospital to ensure they could correctly complete the evaluation after discharge.

\section{Definition of operational procedures}

For cases with thoracoscopic lung resection, a typical 3- or 4-port technique without rib spreading was used. Conventional posterolateral thoracotomy was performed in other cases, and intraoperative conversion was also classified as open surgery. Sublobar resection, including segmentectomy or wedge resection, was conducted in cases with a low tumor malignancy grade or in cases intolerant of lobectomy (19). Complete lymph node dissection indicated the complete removal of all visible lymph nodes and their surrounding tissue from at least three mediastinal lymph node stations (20). All other lymphadenectomies not meeting these criteria were classified as lymph node biopsies.

\section{Statistical analysis}

The data for continuous measures are summarized as means with standard deviations or medians with interquartile ranges. For categorical variables, data are presented as frequencies with percentages. To identifying factors significantly associated with symptom recovery, patients with pain or cough scores higher than the average were compared with those who had scores below the average. Differences between groups were analyzed using twosample $t$-tests or one-way analysis of variance for continuous variables, and Pearson's $\chi^{2}$ tests for categorical variables. Univariate and multivariate analyses were conducted using logistic regression. Statistical significance was set at $\mathrm{P}<0.05$. All statistical analyses were conducted using SPSS version 19.0 software (SPSS, Chicago, IL).

\section{Results}

\section{Patient compliance to the smartphone-based PRO survey}

During the study period, 1,096 patients were admitted to our department for lung surgery and 894 (81.6\%) patients completed the preoperative smartphone registration. From these patients, 68 were excluded as their scheduled lung resections were not performed due to various reasons, including the incidental identification of tumor dissemination during surgery. The remaining 826 (75.4\%) patients were eligible for compliance analysis (Figure 1 and Table S1). Among them, 589 (71.3\%) responded to at least 3 of the 5 postoperative PRO surveys, and their results were collated for symptom-recovery analysis. The clinical and pathological characteristics of the patients with good compliance are listed in Table S2. As revealed on multivariate regression analysis, high compliance rates were more commonly observed in patients with a history of thoracic surgery [ 29 of 29 patients (100\%) vs. 560 of 797 patients $(70.3 \%) ; \mathrm{P}=0.001$ ], a family history of malignant disease [157 of 198 patients (79.3\%) vs. 432 of 628 patients $(68.8 \%) ; \mathrm{P}=0.006]$, and cancer diagnosis [542 of 744 patients $(72.8 \%)$ vs. 47 of 82 patients (57.3\%); $\mathrm{P}=0.003]$. Higher rates of compliance were also observed in patients with higher levels of education (76.1\% vs. $69.1 \%)$, and patients who resided outside of Shanghai (73.9\% vs. $68.1 \%)$. However, the differences in these latter two factors were not significant $(\mathrm{P}=0.058$ and 0.069 , respectively).

\section{Factors affecting postoperative pain}

Overall, the average pain severity following lung surgery gradually declined over time, from $4.1 \pm 2.5$ at 2 weeks to $3.3 \pm 2.4$ at 6 weeks $(\mathrm{P}<0.001)$, and further down to $2.2 \pm 2.0$ at 12 weeks $(\mathrm{P}<0.001)$. The percentage of patients with a pain frequency greater than $50 \%$ of their awake time 


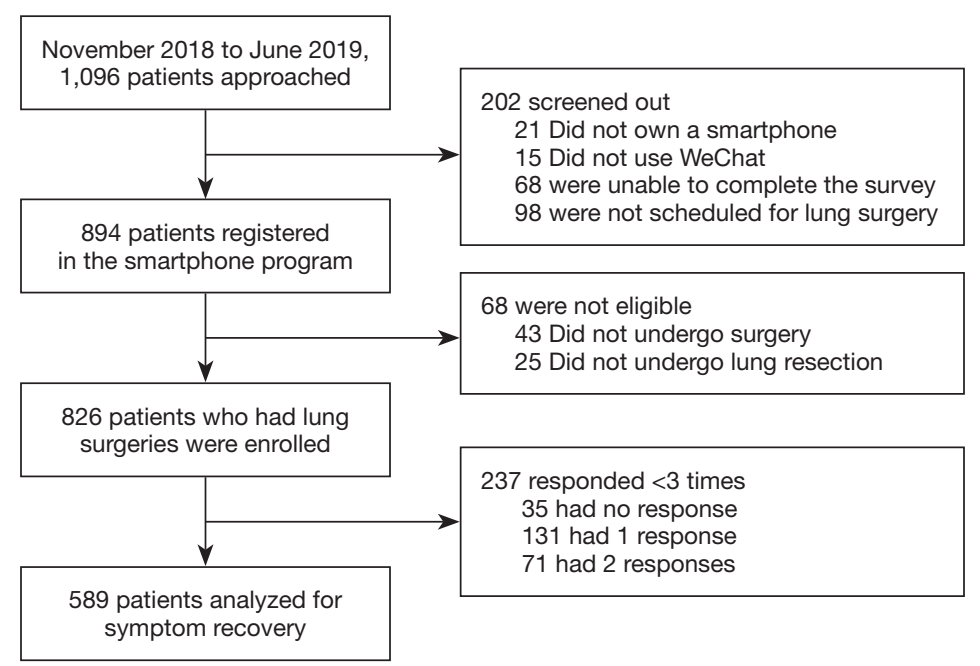

Figure 1 A diagram of the participant screening and exclusion procedure.

Table 1 Factors associated with pain severity at 2, 6, and 12 weeks post-surgery

\begin{tabular}{lccc}
\hline Clinical factors & OR & $95 \% \mathrm{Cl}$ & $\mathrm{P}$ \\
\hline 2 weeks & & & \\
$\quad$ Operative time $>90 \mathrm{~min}$ & 1.461 & $1.039-2.054$ & 0.029 \\
$\begin{array}{l}\text { weeks } \\
\text { Female }\end{array}$ & 1.649 & $1.131-2.404$ & 0.009 \\
Open thoracotomy & 3.024 & $1.570-5.823$ & 0.001 \\
Age $>60$ years & 1.534 & $1.080-2.180$ & 0.017 \\
12 weeks & & & \\
Female & 2.317 & $1.545-3.475$ & $<0.001$ \\
Open thoracotomy & 2.779 & $1.417-5.450$ & 0.003 \\
Age $>60$ years & 1.743 & $1.208-2.516$ & 0.003 \\
Chest tube drainage $>7$ days & 3.613 & $1.958-6.666$ & $<0.001$ \\
\hline
\end{tabular}

OR, odds ratio; $\mathrm{Cl}$, confidence interval.

(categories 3 and 4 ) also decreased from $34.1 \%$ at 2 weeks to $23.8 \%(\mathrm{P}=0.002)$ at 6 weeks, and further decreased to $9.0 \%(\mathrm{P}<0.001)$ at 12 weeks (Figure $\mathrm{S} 1)$.

As revealed in the regression analysis (Table 1 and Table S3), longer operative times ( $>90 \mathrm{~min}$ ) were associated with higher pain scores at 2 weeks $(4.400 \pm 2.571 \mathrm{vs}$. $3.88 \pm 2.478, P=0.017)$. At 6 weeks, higher pain scores were associated with factors including the female sex (3.44 \pm 2.375 vs. $2.95 \pm 2.366, \mathrm{P}=0.019$ ), thoracotomy $(4.47 \pm 2.590$ vs. $3.15 \pm 2.335, \mathrm{P}<0.001)$, and age over
60 years $(3.47 \pm 2.412$ vs. $3.09 \pm 2.346, \mathrm{P}=0.060)$. At 12 weeks, the female sex $(2.38 \pm 2.007$ vs. $2.00 \pm 1.873$, $\mathrm{P}=0.029)$, thoracotomy $(3.15 \pm 1.757$ vs. $2.16 \pm 1.964$, $\mathrm{P}<0.001)$, and age $(2.50 \pm 1.962$ vs. $2.04 \pm 1.949, \mathrm{P}=0.006)$ remained predictors of a higher degree of self-reported pain. Patients with a prolonged drainage time ( $>7$ days) also experienced greater pain severity $(3.21 \pm 2.075$ vs. $2.13 \pm 1.923$, $\mathrm{P}<0.001)$. The association between different factors and the pain recovery patterns in patients is shown in Figure 2.

\section{Factors affecting postoperative cough}

Similar to pain, the self-reported cough scores also decreased over time, from $2.34 \pm 1.30$ at 2 weeks to $2.17 \pm 1.27$ at 6 weeks $(\mathrm{P}<0.01)$, and further decreasing to $1.93 \pm 1.26$ at 12 weeks $(\mathrm{P}<0.001)$. On regression analysis (Table 2 and Table S4), the female sex $(2.50 \pm 1.324$ vs. $2.09 \pm 1.215$; $\mathrm{P}<0.001)$ and complete lymph node dissection $(2.51 \pm 1.29$ vs. $2.1 \pm 1.275 ; \mathrm{P}<0.001$ ) were associated with higher cough scores at 2 weeks. At 6 weeks, longer surgical time ( $>90 \mathrm{~min})$ was also a predictor of increased cough severity $(2.40 \pm 1.203$ vs. $1.99 \pm 1.3 ; \mathrm{P}<0.001)$, whereas sublobar resection was associated with a lower cough score $(1.85 \pm 1.242 \mathrm{vs}$. $2.46 \pm 1.233 ; \mathrm{P}<0.001)$. This association of lymph node dissection, sublobar resection, and surgical time (>90 $\mathrm{min})$ with cough severity was maintained at 12 weeks. Female patients continued to report higher cough scores than male patients $(2.04 \pm 1.259$ vs. $1.74 \pm 1.243 ; \mathrm{P}=0.007)$. However, the severity significantly decreased over time. The cough recovery patterns in patients with the above-mentioned 

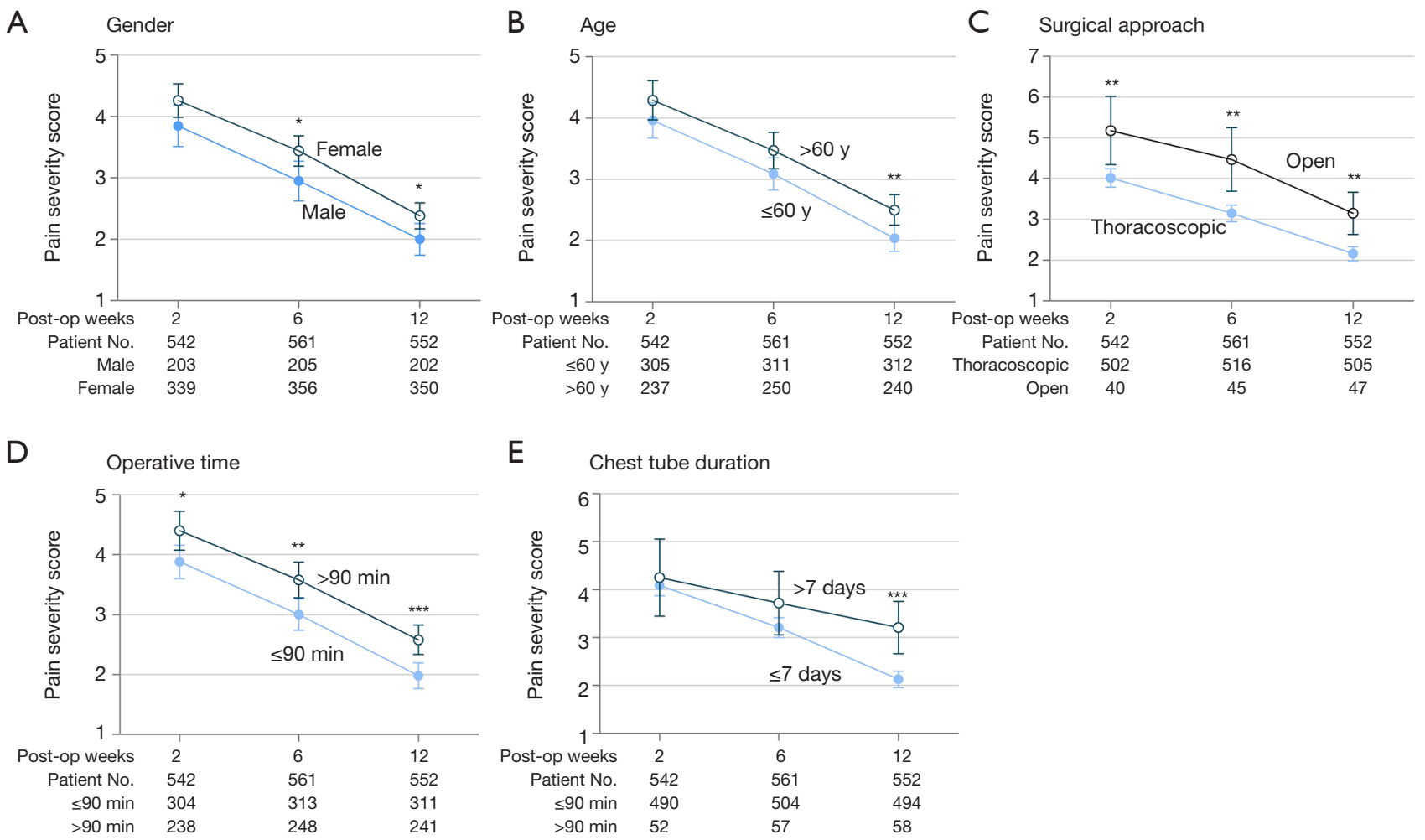

Figure 2 The recovery trajectories of pain by each affecting factors. There were significant differences in the degree of pain during the first 12 weeks in patients grouped by gender (A), age (B), surgical approach (C), operative time (D) and chest tube duration (E). The numbers on the $\mathrm{x}$-axis indicate the number of patients who responded to the surveys. The data are shown as the mean with $95 \%$ confidence interval (CI; error bars). *, $\mathrm{P}<0.05$; ${ }^{* *}, \mathrm{P}<0.01$, and ${ }^{* *}, \mathrm{P}<0.001$ as analyzed by the Student's $t$-test.

predictors are shown in Figure 3.

To further investigate the effects of lymphadenectomy on cough severity, the cough scores of patients who had complete dissection were compared to patients who only underwent biopsy and patients without nodal resection. Although the cough severity remained highest in the dissection group and the lowest in the "no resection" group, the level of cough in the biopsy group was not significantly different from that in the dissection group at 2 weeks (2.51 \pm 1.29 vs. $2.26 \pm 1.257, \mathrm{P}=0.054)$. However, the severity dropped to a similar value to that observed in the "no resection" group at 12 weeks $(1.43 \pm 1.075$ vs. $1.14 \pm 1.336$, $\mathrm{P}=0.081$ ), suggesting that the recovery rate of coughing may be associated with the degree of lymph node resection (Figure 3).

\section{Discussion}

In the present study, a popular messenger application on smartphones was used to collect post-discharge symptom information via PRO surveys. The collated information was analyzed to identify the factors associated with recovery after lung cancer surgery.

Owing to advances in screening and technical procedures, the surgical and oncological outcomes of lung cancer surgery have greatly improved $(21,22)$. Patient satisfaction post-surgery is largely dependent on his or her recovery experience (11). This study demonstrated that the automated collection of patient-reported symptoms using a smartphone-based program was feasible in the continuous monitoring of an individual's recovery after lung surgery. Without extra workload on medical staff, the program successfully captured post-discharge information from a relatively large group of patients $(n=826)$ in a short period of time ( 8 months), and identified factors associated with the differential recovery trajectory following lung surgery. This suggests that a messenger application approach may be incorporated into routine postoperative follow-up and 
Table 2 Factors associated with cough severity at 2, 6, and 12 weeks post-surgery

\begin{tabular}{lccc}
\hline Clinical factors & OR & $95 \% \mathrm{Cl}$ & $\mathrm{P}$ \\
\hline 2 weeks & & & \\
Female & 1.934 & $1.325-2.823$ & 0.001 \\
Lymph node dissection & 2.135 & $1.462-3.117$ & $<0.001$ \\
6 weeks & & & \\
Female & 1.906 & $1.284-2.829$ & 0.001 \\
Sublobar resection & 0.431 & $0.288-0.647$ & $<0.001$ \\
Operative time $>90$ min & 1.493 & $1.001-2.228$ & 0.049 \\
$\begin{array}{l}\text { 12 weeks } \\
\text { Female }\end{array}$ & 1.893 & $1.241-2.888$ & 0.003 \\
Operative time $>90$ min & 1.904 & $1.222-2.967$ & 0.004 \\
Sublobar resection & 0.495 & $0.281-0.872$ & 0.015 \\
Lymph node dissection & 2.992 & $1.688-5.302$ & $<0.001$ \\
\hline
\end{tabular}

OR, odds ratio; $\mathrm{Cl}$, confidence interval. may aid in the provision of a more comprehensive patientcentered evaluation of the surgery $(6,9)$.

Previous studies have shown that regular PRO measures not only reflect the patient experience, but also improve treatment outcomes $(13,14)$. In cancer patients who required surgery or chemotherapy, the addition of symptom-related PRO measures to routine clinical visits significantly diminished symptom severity (5), increased the patient's tolerance to chemotherapy $(13,15)$, and improved oncological outcomes $(14,15)$. Nevertheless, conducting such studies is highly labor-intensive, and variations in the quality and frequency of follow-up at different clinical sites may lead to limited interpretability $(9,11)$. The results may also have lower generalizability in patients who have difficulties visiting the hospital (9). While symptom-related follow-up by telephone calls may lead to better control of variations and a reduction in logistical costs, it is timeconsuming. In addition, the presence of bias towards elderly patients who may need more assistance and time to
A

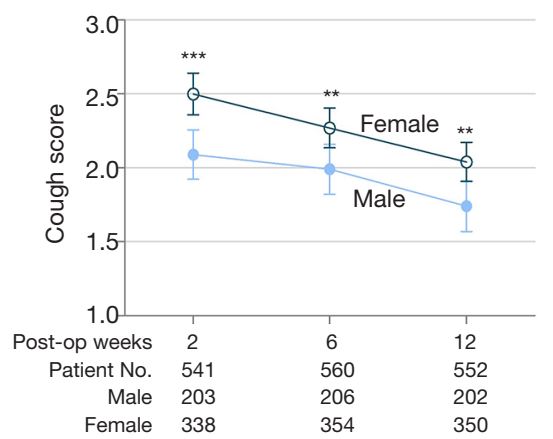

D

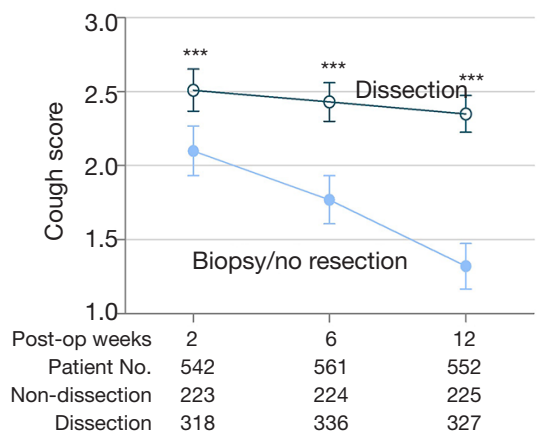

B

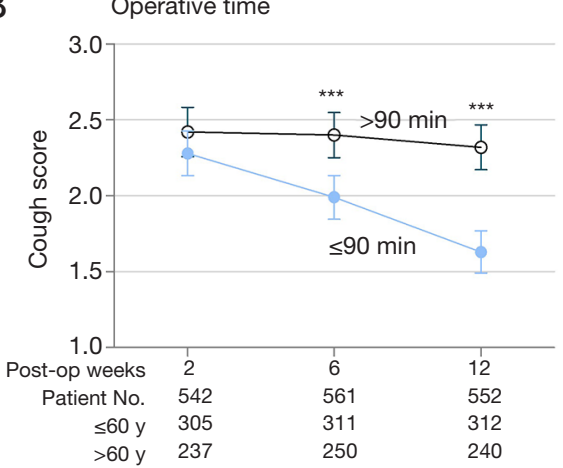

E

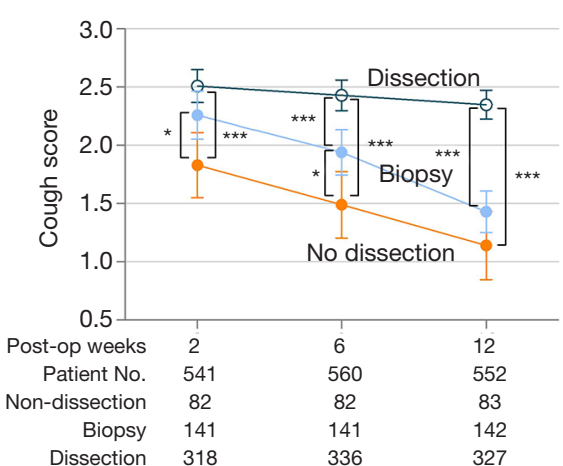

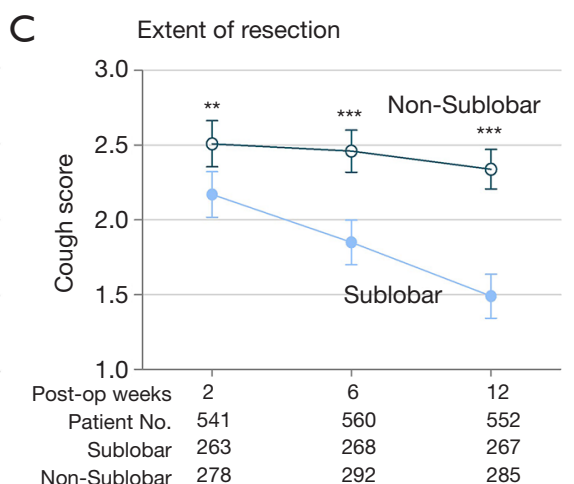

Non-Sublobar 278

285

Figure 3 The recovery trajectories of cough severity by its affecting factors. Cough severity during the first 12 weeks after lung surgery decreased in different patterns in patients grouped by gender (A), operative time (B), extent of resection (C) and type of lymph node resection $(\mathrm{D}, \mathrm{E})$. The numbers on the $\mathrm{x}$-axis indicate the number of patients who responded to the surveys. The data are shown as means with $95 \%$ confidence interval (CI; error bars). ${ }^{*}, \mathrm{P}<0.05$; ${ }^{* *}, \mathrm{P}<0.01$, and ${ }^{* * *}, \mathrm{P}<0.001$ as analyzed by the Student's $t$-test. 
complete the survey cannot be excluded $(8,23)$. Therefore, despite the benefits, incorporating PRO measures into routine clinical practice and large-scale research remains a challenge.

To address these challenges, our smartphone applicationbased program was designed to collect symptom-related PRO results with reduced labor costs and minimal variations in follow-up. WeChat is a widely used multi-function messaging application which supports instant online communication in various formats including text, image, voice message and videos. Therefore, it provides a more convenient tool than the traditional tools such as telephone, email, or web page that were used for PRO collection in previous studies $(8,14,15)$. Of all the in-hospital patients requiring lung surgery during the study period, $75.4 \%$ were enrolled and $71.3 \%$ of the enrolled patients responded to at least 3 of the 5 post-discharge surveys. While some previous studies have also used smartphones or wearable devices for the remote collection of patient-generated data after surgeries for lung, breast, gastric or other cancers (23), many of them required patients to use new applications that they may not be familiar with, which may lead to lower response rates $(24,25)$. Concerns regarding data privacy may also contribute lower participation rates. In comparison, this study used a self-designed program built on a popular multifunctional application that most patients and their relatives use daily and therefore, patients did not have to adapt to a new application on the smartphone. The symptom-related surveys were sent directly to and from our departmental WeChat Service account, and patients were usually willing to be connected to this account. All information was kept strictly for research purposes only. None of the patients refused to register in the program due to concerns pertaining to privacy. Patients with malignant disease and prior thoracic surgery showed a better response rate indicating that compliance may be affected by the patient's knowledge and presumption of disease severity.

The current lung cancer guidelines recommend the initiation of surveillance at 6 months after surgery for the detection of recurrence signs (26). Although patients' symptoms and experience after surgery are also of great importance, few studies to date have focused on symptom recovery in patients following lung surgery. Such information on recovery can be used to further improve quality of the surgery and enhance recovery. Using a telephone call-based tool (MD Anderson Symptom Inventory), Fagundes et al. evaluated the recovery of 60 patients after lung surgery by analyzing 13 symptoms, and found that by 3 months, most of the symptoms had significantly ameliorated (8). In agreement with prior randomized trials (3), Fagundes and colleagues found that thoracotomy was related to more severe postoperative pain, supporting the sensitivity and credibility of the phone-based tool. Our current investigation using a larger population concurred with the latter study. Moreover, more intensive surveillance may detect early relapse in patient with more advanced lung cancer after chemotherapy, potentially leading to improved survival $(15,27)$. Nevertheless, whether the current method can detect early recurrence after surgery in patient with early-stage lung cancer is beyond the scope of this study but certainly worth further investigation.

In our study cohort, surgical time and chest tube duration was independently associated with postoperative pain, possibly owing to prolonged irritation of the intercostal nerves (28). Gender was also associated with differential pain and cough severity and this may reflect a higher sensitivity to nerve irritation in female patients $(29,30)$. Other factors affecting cough included the extent of lung resection, the type of lymphadenectomy, and surgical time, all of which are surgery-related. As the benefits of minimally invasive techniques such as sublobar resection and limited lymphadenectomy may not be uncovered by studies assessing traditional perioperative metrics (such as morbidity and mortality) $(21,22,31)$, evidence of their value in improving patient recovery experiences may highlight the need for more individualized oncological surgery to achieve better outcomes $(4,32)$. Notably, operative time was an independent factor associated with recovery. Therefore, any new technique that attempts to reduce surgical invasiveness at the cost of prolonged surgical time should be carefully evaluated for their true benefits to patients. Moreover, it should be emphasized that even if some of the factors can be modified, one should not opt for these approaches without fully realizing the potential impacts on the oncological efficacy of the surgery.

\section{Limitations}

This study has several limitations. First, all the participants were required to have a smartphone and be able to use the WeChat application. Reasons why the patients could not use this program on WeChat were not investigated in the current study because some critical information such as education status, family status and income status were not collected. Although this potentially limits the generalizability of our findings, the rate of smartphone 
ownership has increased dramatically in countries such as the United States and China (24). Also, there are other applications such as WhatsApp and Facebook which are highly popular and have similar functions to those of WeChat, which makes it possible for the design of this study to be replicated elsewhere in the world. Second, the study was performed in a high-volume tertiary center specializing in thoracic diseases. Whether similar patient compliance can be achieved in other care units with fewer resources requires further validation. Third, although pain and cough medication is routinely prescribed to patients after discharge, in this study, patients were not required to record their medication use (such as dose and frequency) in detail and this may have had an impact on the results. These information are also important to identify effective medication to improve recovery after lung surgery. Fourth, although our results echoed with previous studies using telephone to collect PRO after lung surgery, how to validate accuracy of the PRO results may be an innate limitation of these studies (33). However, it is believed that PRO provide essential information that cannot be reliably captured any other way about the patient experience and the results are generally trustworthy (33). Finally, this was a singlearm observational study and no standard intervention was conducted based on the patient's feedback. Further randomized trials are required to investigate any benefits associated with the implementation of this PRO monitoring system in terms of improved symptom control and patient satisfaction.

\section{Conclusions and future perspective}

In conclusion, smartphone-based PRO surveillance following lung surgery is feasible and enables the monitoring of symptoms to complement traditional follow-up strategies. As surgery-related factors may alter the patient recovery trajectory, future assessments of new surgical techniques should also include PRO-related metrics to better evaluate their benefits and costs. This may facilitate the development of more optimized and individualized surgical strategies.

\section{Acknowledgments}

The authors thank all the nurses (Ms. Juan Chen, Ms. Liang Feng, Ms. Zhengmin Zhang, and Miss Yazhi Zhao) for their role in patient education and coordinating the project. Part of this work was orally presented at the $60^{\text {th }}$
Annual Meeting of Japanese Lung Cancer Society (Osaka, 7 December 2019), and has been accepted to be presented at the $1^{\text {st }}$ European Society of Thoracic Surgery (ESTS) Virtual Meeting (2-3 October 2020) as a poster.

Funding: This work was supported by grants from the Shanghai Municipal Health Commission (Grant numbers 2018YQ61 and 2019SY047), the Science and Technology Commission of Shanghai Municipality (Grant number 18441901500), and the National Natural Science Foundation of China (Grant numbers 82073191 and 81502480 ) awarded to XC.

\section{Footnote}

Reporting Checklist: The authors have completed the STROBE reporting checklist. Available at http://dx.doi. org/10.21037/jtd-21-27

Data Sharing Statement: Available at http://dx.doi. org/10.21037/jtd-21-27

Conflicts of Interest: All authors have completed the ICMJE uniform disclosure form (available at http://dx.doi. org/10.21037/jtd-21-27). XC reports that he has a patent 2018SR891901 licensed. The other authors have no conflicts of interest to declare.

Ethical Statement: The authors are accountable for all aspects of the work in ensuring that questions related to the accuracy or integrity of any part of the work are appropriately investigated and resolved. This study was approved by the institutional Ethics Review Committee of the Shanghai Chest Hospital (approval number KSY1871). Digital consent was obtained after the patients agreed to connect their accounts with our departmental public service account on WeChat by scanning a quick response code. This study conformed to the provisions of the Declaration of Helsinki (as revised in 2013).

Open Access Statement: This is an Open Access article distributed in accordance with the Creative Commons Attribution-NonCommercial-NoDerivs 4.0 International License (CC BY-NC-ND 4.0), which permits the noncommercial replication and distribution of the article with the strict proviso that no changes or edits are made and the original work is properly cited (including links to both the formal publication through the relevant DOI and the license). See: https://creativecommons.org/licenses/by-nc-nd/4.0/. 


\section{References}

1. Rose J, Weiser TG, Hider P, et al. Estimated need for surgery worldwide based on prevalence of diseases: a modelling strategy for the WHO Global Health Estimate. Lancet Glob Health 2015;3 Suppl 2:S13-20.

2. Yang P, Cheville AL, Wampfler JA, et al. Quality of life and symptom burden among long-term lung cancer survivors. J Thorac Oncol 2012;7:64-70.

3. Bendixen M, Jorgensen OD, Kronborg C, et al. Postoperative pain and quality of life after lobectomy via video-assisted thoracoscopic surgery or anterolateral thoracotomy for early stage lung cancer: a randomised controlled trial. Lancet Oncol 2016;17:836-44.

4. Cheng X, Onaitis MW, D'Amico TA, et al. Minimally Invasive Thoracic Surgery 3.0: Lessons Learned From the History of Lung Cancer Surgery. Ann Surg 2018;267:37-8.

5. Cleeland CS, Wang XS, Shi Q, et al. Automated symptom alerts reduce postoperative symptom severity after cancer surgery: a randomized controlled clinical trial. J Clin Oncol 2011;29:994-1000.

6. Fry BT, Campbell DA Jr, Englesbe MJ, et al. Using Patient-reported Outcomes to Enhance Appropriateness in Low-risk Elective General Surgery. Ann Surg 2019;269:41-2.

7. Schneider BJ, Ismaila N, Aerts J, et al. Lung Cancer Surveillance After Definitive Curative-Intent Therapy: ASCO Guideline. J Clin Oncol 2020;38:753-66.

8. Fagundes CP, Shi Q, Vaporciyan AA, et al. Symptom recovery after thoracic surgery: Measuring patientreported outcomes with the MD Anderson Symptom Inventory. J Thorac Cardiovasc Surg 2015;150:613-9.e2.

9. Tung S, Davis LE, Hallet J, et al. PopulationLevel Symptom Assessment Following Pancreaticoduodenectomy for Adenocarcinoma. JAMA Surg 2019;154:e193348.

10. Sawabata N, Maeda H, Takeda S, et al. Persistent cough following pulmonary resection: observational and empiric study of possible causes. Ann Thorac Surg 2005;79:289-93.

11. Bilimoria KY, Cella D, Butt Z. Current Challenges in Using Patient-Reported Outcomes for Surgical Care and Performance Measurement: Everybody Wants to Hear From the Patient, but Are We Ready to Listen? JAMA Surg 2014;149:505-6.

12. Basch E. Patient-Reported Outcomes - Harnessing Patients' Voices to Improve Clinical Care. N Engl J Med 2017;376:105-8.
13. Basch E, Deal AM, Kris MG, et al. Symptom Monitoring With Patient-Reported Outcomes During Routine Cancer Treatment: A Randomized Controlled Trial. J Clin Oncol 2016;34:557-65.

14. Basch E, Deal AM, Dueck AC, et al. Overall Survival Results of a Trial Assessing Patient-Reported Outcomes for Symptom Monitoring During Routine Cancer Treatment. JAMA 2017;318:197-8.

15. Denis F, Lethrosne C, Pourel N, et al. Randomized Trial Comparing a Web-Mediated Follow-up With Routine Surveillance in Lung Cancer Patients. J Natl Cancer Inst 2017;109. doi: 10.1093/jnci/djx029.

16. Rauwerdink A, Jansen M, de Borgie C, et al. Improving enhanced recovery after surgery (ERAS): ERAS APPtimize study protocol, a randomized controlled trial investigating the effect of a patient-centred mobile application on patient participation in colorectal surgery. BMC Surg 2019;19:125.

17. von Elm E, Altman DG, Egger M, et al. The Strengthening the Reporting of Observational Studies in Epidemiology (STROBE) statement: guidelines for reporting observational studies. Lancet 2007;370:1453-7.

18. Irwin RS, Baumann MH, Bolser DC, et al. Diagnosis and management of cough executive summary: ACCP evidence-based clinical practice guidelines. Chest 2006;129:1S-23S.

19. Detterbeck FC, Lewis SZ, Diekemper R, et al. Executive Summary: Diagnosis and management of lung cancer, 3rd ed: American College of Chest Physicians evidence-based clinical practice guidelines. Chest 2013;143:7S-37S.

20. Darling GE, Allen MS, Decker PA, et al. Randomized trial of mediastinal lymph node sampling versus complete lymphadenectomy during pulmonary resection in the patient with N0 or N1 (less than hilar) non-small cell carcinoma: results of the American College of Surgery Oncology Group Z0030 Trial. J Thorac Cardiovasc Surg 2011;141:662-70.

21. Altorki NK, Wang X, Wigle D, et al. Perioperative mortality and morbidity after sublobar versus lobar resection for early-stage non-small-cell lung cancer: post-hoc analysis of an international, randomised, phase 3 trial (CALGB/Alliance 140503). Lancet Respir Med 2018;6:915-24.

22. Suzuki K, Saji H, Aokage K, et al. Comparison of pulmonary segmentectomy and lobectomy: Safety results of a randomized trial. J Thorac Cardiovasc Surg 2019;158:895-907.

23. Phillips JD, Wong SL. Patient-Reported Outcomes in 
Surgical Oncology: An Overview of Instruments and Scores. Ann Surg Oncol 2020;27:45-53.

24. Panda N, Solsky I, Huang EJ, et al. Using smartphones to capture novel recovery metrics after cancer surgery. JAMA Surg 2020;155:123-9.

25. Pevnick JM, Fuller G, Duncan R, et al. A Large-Scale Initiative Inviting Patients to Share Personal Fitness Tracker Data with Their Providers: Initial Results. PLoS One 2016;11:e0165908.

26. Watanabe K, Tsuboi M, Sakamaki K, et al. Postoperative follow-up strategy based on recurrence dynamics for non-small-cell lung cancer. Eur J Cardiothorac Surg 2016;49:1624-31.

27. Calman L, Beaver K, Hind D, et al. Survival benefits from follow-up of patients with lung cancer: a systematic review and meta-analysis. J Thorac Oncol 2011;6:1993-2004.

28. Koehler RP, Keenan RJ. Management of postthoracotomy pain: acute and chronic. Thorac Surg Clin 2006;16:287-97.

29. Dicpinigaitis PV, Rauf K. The influence of gender on

Cite this article as: Cheng X, Yang Y, Shentu Y, Ding Z, Zhou Q, Tan Q, Luo Q. Remote monitoring of patient recovery following lung cancer surgery: a messenger application approach. J Thorac Dis 2021;13(2):1162-1171. doi: 10.21037/jtd$21-27$ cough reflex sensitivity. Chest 1998;113:1319-21.

30. Kampe S, Wendland M, Welter S, et al. Independent predictors for higher postoperative pain intensity during recovery after open thoracic surgery: a retrospective analysis in 621 patients. Pain Med 2018;19:1667-73.

31. Allen MS, Darling GE, Pechet TT, et al. Morbidity and mortality of major pulmonary resections in patients with early-stage lung cancer: initial results of the randomized, prospective ACOSOG Z0030 trial. Ann Thorac Surg 2006;81:1013-9; discussion 1019-20.

32. Poghosyan H, Sheldon LK, Leveille SG, et al. Healthrelated quality of life after surgical treatment in patients with non-small cell lung cancer: a systematic review. Lung Cancer 2013;81:11-26.

33. Atkinson TM, Wagner JS, Basch E. Trustworthiness of Patient-Reported Outcomes in Unblinded Cancer Clinical Trials. JAMA Oncol 2017;3:738-9.

(English Language Editor: J. Teoh) 
Table S1 Geographic characteristics of the enrolled patients

\begin{tabular}{|c|c|c|c|c|}
\hline \multirow{2}{*}{ Clinical features } & \multirow{2}{*}{$\begin{array}{l}\text { Poor compliance }{ }^{a} \\
\qquad(\mathrm{~N}=237)\end{array}$} & \multirow{2}{*}{$\begin{array}{l}\text { Good compliance } \\
\qquad(\mathrm{N}=589)\end{array}$} & \multicolumn{2}{|c|}{$P$ value } \\
\hline & & & Univariate & Multivariate \\
\hline \multicolumn{5}{|l|}{ Gender } \\
\hline Male & $90[29]$ & $216[71]$ & 0.75 & 0.89 \\
\hline Female & $147[28]$ & 373 [72] & & \\
\hline Age, median [IQR] & $59[50,66]$ & $59[49,66]$ & & \\
\hline$\leq 60$ years & $121[27]$ & $331[73]$ & 0.142 & 0.13 \\
\hline$>60$ years & $116[31]$ & $258[69]$ & & \\
\hline Education & & & 0.047 & 0.058 \\
\hline$\geq$ College & 62 [24] & $197[76]$ & & \\
\hline$\leq$ High school & $175[31]$ & $392[69]$ & & \\
\hline Local residents & & & 0.075 & 0.069 \\
\hline Yes & 118 [32] & $252[68]$ & & \\
\hline No & $119[26]$ & $337[74]$ & & \\
\hline Comorbidities & & & 0.687 & 0.424 \\
\hline Yes & 86 [30] & 204 [70] & & \\
\hline No & $151[28]$ & 385 [72] & & \\
\hline History of surgery & & & 0.017 & 0.142 \\
\hline Yes & 93 [25] & $286[76]$ & & \\
\hline No & $144[32]$ & $303[68]$ & & \\
\hline History of thoracic surgery & & & $<0.001$ & 0.001 \\
\hline Yes & 0 & 29 [100] & & \\
\hline No & $237[30]$ & $560[70]$ & & \\
\hline History of malignant tumor & & & 0.741 & 0.73 \\
\hline Yes & $12[26]$ & $34[74]$ & & \\
\hline No & 225 [29] & $555[71]$ & & \\
\hline Family history of malignant diseases & & & 0.004 & 0.006 \\
\hline Yes & $41[21]$ & $157[79]$ & & \\
\hline No & $196[31]$ & $432[69]$ & & \\
\hline Type of surgery & & & 1 & 0.915 \\
\hline Open thoracotomy & 19 [29] & $47[71]$ & & \\
\hline Thoracoscopic surgery & $118[18]$ & $542[82]$ & & \\
\hline Pathology of the lesion & & & 0.004 & 0.003 \\
\hline Malignant & $202[27]$ & $542[73]$ & & \\
\hline Benign & 35 [43] & $47[57]$ & & \\
\hline Postoperative stay & & & 0.527 & 0.675 \\
\hline$>7$ days & 27 [32] & 58 [68] & & \\
\hline$\leq 7$ days & $210[28]$ & $531[72]$ & & \\
\hline
\end{tabular}

${ }^{a}$, poor compliance was defined as a response to less than 3 of the 5 postoperative surveys; ${ }^{b}$, good compliance was defined as a response to at least 3 postoperative surveys. IQR, interquartile range. 
Table S2 Clinical characteristics of patients included for analysis of symptom recovery

Patient No. [\%] $]^{\mathrm{a}} \mathrm{N}=589$

Preoperative FEV1 \%

$474[80]$

$\geq 80 \%$

$<80 \%$

115 [20]

PS score

1-2

BMI

$\geq 24$

$<24$

Comorbidities

Total

Respiratory

Cardiovascular

Surgical history

Total

Thoracic

Smoking history

Yes

Surgical approach

Thoracoscopic

Open

Laterality of surgery

Right

Bilateral

Extent of resection

Sublobar

Wedge resection

Segmentectomy

Non-sublobar

Lobectomy

Sleeve resection

Bilobectomy

Pneumonectomy

LN removed, median [IQR]

$510[87]$

79 [13]

203 [34]

386 [66]

207 [35]

35 [6]

$161[27]$

295 [50]

$29[5]$

169 [29]

$420[71]$

542 [92]

$47[8]$

336 [57]

$247[42]$

$6[1]$

$283[48]$

$201[34]$

$82[14]$

306 [52]

$285[48]$

4 [1]

12 [2]

$5[1]$

$6[2,11]$

$4[2,6]$

N stations removed, median [IQR]

Type of LN removal

Dissection

350 [60]

$10[7,14]$

$6[5,7]$

$150[25]$

$3[2,4]$

$\begin{array}{ll}\text { LN stations removed, median [IQR] } & 2[2,3] \\ \text { o resection } & 89[15]\end{array}$

$\begin{array}{ll}\text { LN stations removed, median [IQR] } & 2[2,3] \\ \text { o resection } & 89[15]\end{array}$

Operative time, median [IQR], minutes $\quad 85[60,113]$

Surgical time $>90 \mathrm{~min} \quad 263[45]$

Chest tube duration, median [IQR], days $3[2,5]$

Drainage $>7$ days $58[10]$

Postoperative complications $\quad 79[13]$

Tumor size, median [IQR], cm $\quad 1.2[0.7,2.1]$

Tumor histology

Adenocarcinoma 501 [85]

Squamous cell carcinoma 30 [5]

Small cell carcinoma 4 [1]

Other malignant $\quad 13[2]$

Metastatic tumor $2[0.3]$

Benign $39[7]$

pStage

AAH/AIS $113[19]$

IA $344[58]$

IB $38[6]$

IIA

IIB $8[1]$

IIIA $29[5]$

IIIB 5 [1]

a, data denote No. [\%] unless otherwise indicated. FEV1, forced expiratory volume in one second; PS, performance status; BMI, body mass index; LN, lymph nodes; IQR, interquartile range; AAH, atypical adenomatous hyperplasia; AIS, adenocarcinoma in situ.

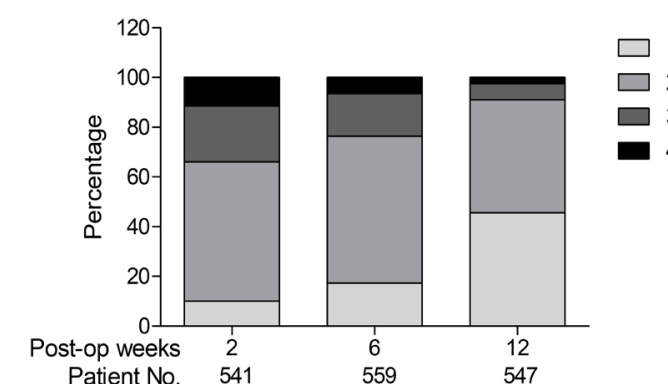

Figure S1 The distribution of patients with varied pain frequency during the study period, with 1 denoting "not present", 2 denoting "rare, less than $50 \%$ of awake time", 3 denoting "sometimes, more than $50 \%$ of awake time", and 4 denoting "always". 
Table S3 Regression analysis of the factors associated with higher pain severity post-surgery

\begin{tabular}{|c|c|c|c|c|c|c|}
\hline \multirow{2}{*}{ Clinical variables } & \multicolumn{3}{|c|}{$P$ value (univariate) } & \multicolumn{3}{|c|}{$\mathrm{P}$ value (multivariate) } \\
\hline & 2 weeks & 6 weeks & 12 weeks & 2 weeks & 6 weeks & 12 weeks \\
\hline Gender (female) & 0.328 & 0.106 & 0.011 & 0.174 & 0.009 & $<0.001$ \\
\hline Age (>60 years) & 0.057 & 0.012 & 0.001 & 0.127 & 0.017 & 0.003 \\
\hline $\mathrm{BMI}\left(\geq 24 \mathrm{~kg} / \mathrm{m}^{2}\right)$ & 0.588 & 0.317 & 0.927 & 0.789 & 0.267 & 0.752 \\
\hline Surgical approach (thoracotomy) & 0.049 & 0.001 & $<0.001$ & 0.122 & 0.001 & 0.002 \\
\hline Side of surgery (left) & 0.426 & 0.051 & 0.166 & 0.656 & 0.776 & 0.883 \\
\hline Chest tube duration ( $>7$ days) & 1 & 0.032 & $<0.001$ & 0.746 & 0.104 & $<0.001$ \\
\hline PS score $(\geq 1)$ & 0.439 & 0.045 & 0.101 & 0.457 & 0.09 & 0.446 \\
\hline \multicolumn{7}{|l|}{ Comorbidity } \\
\hline Diabetes & 0.652 & 0.647 & 0.211 & 0.516 & 0.827 & 0.298 \\
\hline Total & 0.529 & 0.717 & 0.272 & 0.656 & 0.671 & 0.691 \\
\hline \multicolumn{7}{|l|}{ Surgical history } \\
\hline Thoracic & 0.252 & 0.838 & 0.687 & 0.139 & 0.606 & 0.697 \\
\hline Total & 0.863 & 1 & 0.383 & 0.933 & 0.632 & 0.521 \\
\hline Operative time (>90 min) & 0.031 & 0.045 & 0.001 & 0.029 & 0.268 & 0.079 \\
\hline Postoperative complications & 1 & 0.527 & 0.043 & 0.474 & 0.707 & 0.102 \\
\hline
\end{tabular}

Italic values indicate significant difference. BMI, body mass index; PS, performance status.

Table S4 Regression analysis of the factors associated with cough severity following lung surgery

\begin{tabular}{|c|c|c|c|c|c|c|}
\hline \multirow{2}{*}{ Clinical variables } & \multicolumn{3}{|c|}{$P$ value (univariate) } & \multicolumn{3}{|c|}{$\mathrm{P}$ value (multivariate) } \\
\hline & 2 weeks & 6 weeks & 12 weeks & 2 weeks & 6 weeks & 12 weeks \\
\hline Gender (female) & $<0.001$ & 0.007 & 0.042 & 0.001 & 0.001 & 0.003 \\
\hline Age (>60 years) & 0.051 & 0.664 & 0.002 & 0.013 & 0.17 & 0.350 \\
\hline $\mathrm{BMI}\left(\geq 24 \mathrm{~kg} / \mathrm{m}^{2}\right)$ & 0.586 & 0.786 & 0.665 & 0.419 & 0.471 & 0.317 \\
\hline Preoperative FEV1\% (<80\%) & 0.092 & 0.237 & 0.361 & 0.224 & 0.267 & 0.238 \\
\hline \multicolumn{7}{|l|}{ Comorbidity } \\
\hline Respiratory & 1 & 0.725 & 0.987 & 0.424 & 0.517 & 0.927 \\
\hline Total & 0.367 & 0.366 & 0.212 & 0.731 & 0.391 & 0.761 \\
\hline \multicolumn{7}{|l|}{ Surgical history } \\
\hline Thoracic & 0.704 & 0.839 & 0.229 & 0.776 & 0.482 & 0.942 \\
\hline Total & 0.546 & 0.666 & 0.421 & 0.254 & 0.21 & 0.473 \\
\hline Smoking history & 0.001 & 0.036 & 0.217 & 0.723 & 0.941 & 0.885 \\
\hline Side of the surgery (left) & 0.137 & 0.18 & 0.393 & 0.776 & 0.211 & 0.727 \\
\hline Extent of resection (sublobar) & 0.016 & $<0.001$ & $<0.001$ & 0.351 & $<0.001$ & 0.016 \\
\hline Lymph node removal (dissection) & 0.002 & $<0.001$ & $<0.001$ & $<0.001$ & 0.289 & $<0.001$ \\
\hline Chest tube duration ( $>7$ days) & 0.662 & 0.319 & 0.190 & 0.501 & 0.351 & 0.973 \\
\hline Operative time (>90 min) & 0.487 & 0.004 & $<0.001$ & 0.85 & 0.049 & 0.005 \\
\hline Postoperative complications & 0.801 & 0.45 & 0.045 & 0.756 & 0.231 & 0.776 \\
\hline
\end{tabular}

Italic values indicate significant difference. BMI, body mass index; FEV1, forced expiratory volume in one second. 